\title{
Influence of trematode infections on in situ growth rates of Littorina littorea
}

\author{
Kim N. Mouritsen*, A. Gorbushin ${ }^{\dagger}$ and K. Thomas Jensen* \\ *Department of Marine Ecology, Institute of Biological Sciences, Aarhus University, Finlandsgade 14, DK-8200 Aarhus N, Denmark. \\ ${ }^{\dagger}$ Department of Invertebrate Zoology, St Petersburg State University, Universitetskaya nab 7/9, 199034 St Petersburg, Russia
}

\begin{abstract}
The influence of various species of digenean trematodes on the in situ growth rate of Littorina littorea (Gastropoda: Prosobranchia) from different habitats was investigated. The main results showed: (1) that infections either reduced or had no significant effect on growth in comparison with uninfected snails; (2) that the same type of infection could have a differential effect on growth depending on the habitat/population from which the snails originated. These findings are consistent with the life history hypothesis expecting no or a stunting effect of trematode infections on the growth of longer-lived snails, but do also emphasize that growth rates following trematode invasion can be significantly modified by environmental conditions, such as, food availability.
\end{abstract}

\section{INTRODUCTION}

Since Wesenberg-Lund (1934) reported that trematode infected snails attained a larger size than uninfected specimens (gigantism), there has been much controversy regarding the effect of trematode infection on snail growth. Several studies have provided evidence of increased growth rates among infected specimens (Rothschild \& Rothschild, 1939; McClelland \& Bourns, 1969; Meuleman, 1972; Sluiters et al., 1980; Wilson \& Denison, 1980; Mouritsen \& Jensen, 1994; Gorbushin, 1997) whereas others have shown no or a stunting effect of trematode infections (Sturrock \& Sturrock, 1970; Sousa, 1983; Crews \& Yoshing, 1989; Fernández \& Esch, 1991). In view of these discrepancies, Fernández \& Esch (1991) have questioned that parasite-induced growth increment takes place in situ mainly because mark-recapture field studies have failed to show gigantism in infected specimens, and because laboratory studies on the same hostparasite association have reached contradictive conclusions. They suspect that evidence of parasite-induced gigantism from laboratory work is a result of providing the snails with ad libitum food supply. However, Mouritsen \& Jensen (1994) argued that their laboratory evidence of gigantism in Hydrobia ulvae could be extrapolated to the field, supported also by Huxham et al. (1995). The decisive field evidence for gigantism in $H$. ulvae is, however, presented by Gorbushin (1997). In several populations from the White Sea, he was able to identify winter lines on the shells of Hydrobia, and could therefore measure directly and accurately annual growth rates of infected and uninfected specimens. This work shows that several species of trematodes do induce enhanced growth in Hydrobia, and hence, confirms that gigantism is a naturally occurring phenomenon.

However, it still remains to be clarified why many studies have reached contradictive results regarding the effect of parasites on snail growth. Sousa (1983) who reviewed the subject, suggested that whether or not gigantism evolves following trematode infection depends on the particular life history of the snail. Believing that gigantism is basically an energetic question, he expected that the obligatory castration of the infected snail released energy previously allocated to reproduction. Longer-lived iteroparous snail species may invest less energy in reproduction on an annual basis than shorterlived semelparous species, and the latter should therefore develop gigantism because the castration would release enough energy for both parasites and additional growth. In the case of an iteroparous species, however, sufficient energy for both parasites and additional growth would not be released, and such snails might therefore experience no or stunting effect on growth if parasitized. Next to life history variation, other factors may also influence growth rates following parasitic invasion, such as the age of the snail and the species of trematode (e.g. Sousa, 1983; Fernández \& Esch, 1991; Gorbushin, 1997). Mouritsen \& Jensen (1994) also argued that the balance between energy intake or saving and the energy demand of the parasites following castration should affect growth rates. It was therefore expected that the growth rate of infected specimens is related to food availability within a given habitat, and hence, vary between populations.

It has not yet been clarified whether or not gigantism develops in trematode-infected Littorina littorea (L.) neither in the laboratory nor in the field. By using the method of measuring growth rates from growth interruption lines on the snails' shell, the present study aimed at testing two expectations: (1) trematode infection in L. littorea as a longer-lived iteroparous snail species have no or a stunting effect on growth, supporting the hypothesis of a life history dependent effect of the parasites; (2) the effect of trematode infection on growth differ between 
snail populations expected to experience different environmental conditions, including food availability.

\section{MATERIALS AND METHODS}

\section{Sampling of snails}

Specimens of Littorina littorea were collected from three different localities in Denmark, October 1995 (Figure 1). One hundred and fifty-four snails were collected on a west facing stone jetty at Rønbjerg Harbour, in the Limfjord (Rønbjerg population), 109 were collected on a west facing stony beach $3 \mathrm{~km}$ south of Rønbjerg Harbour (Trend population), and 164 were obtained from an east facing harbour entrance at Grenå Harbour, the easternmost point of Jutland (Grenå population). Mainly larger individuals were collected in order to maximize the probability of finding infected individuals. Following collection, the snails were immediately brought to the laboratory, measured, and dissected.

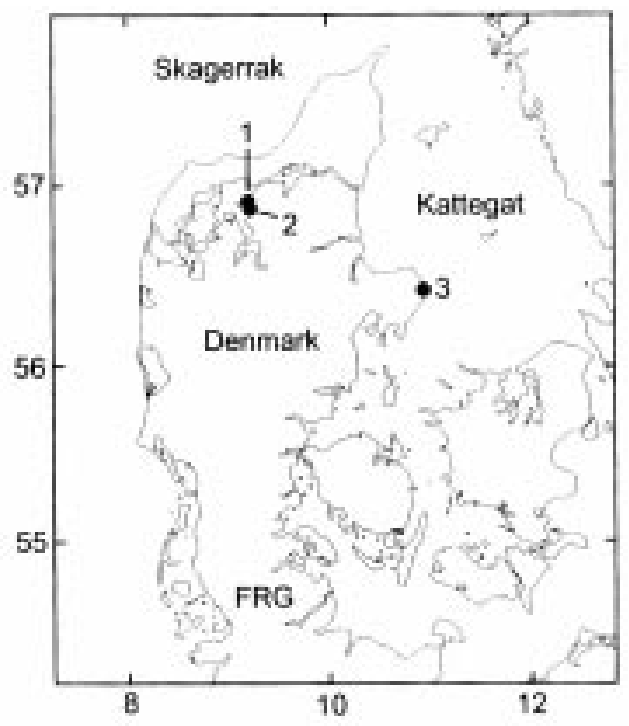

Figure 1. The sites of Littorina littorea collection Rønbjerg (1), Trend (2), Grenå (3).

\section{Measurements and dissection}

Prior to dissection, the last growth interruption line (winter line) was identified on the shell of each specimen and the shell diameter at this point was determined to the nearest $0.1 \mathrm{~mm}\left(\mathrm{~d}_{0}\right.$; Figure 2$)$. The growth of the shell from the winter line to the rim of the shell aperture was then determined in terms of angle increment with $2^{\circ}$ accuracy $(\Delta \varphi$; Figure 2$)$. Measurements were carried out under a stereomicroscope on the vertically orientated snail using an ocular micrometer provided with an angle meter.

Following measurements, the shells were crushed and the specimens sexed according to the presence or absence of a penis. Also the size of the penis was estimated by measuring the length from base to tip under the stereomicroscope. The abdominal soft parts of the specimens were subsequently dissected in order to verify the presence or absence of trematode infections. Parasites were identified to species or genus level according to Werding (1969).

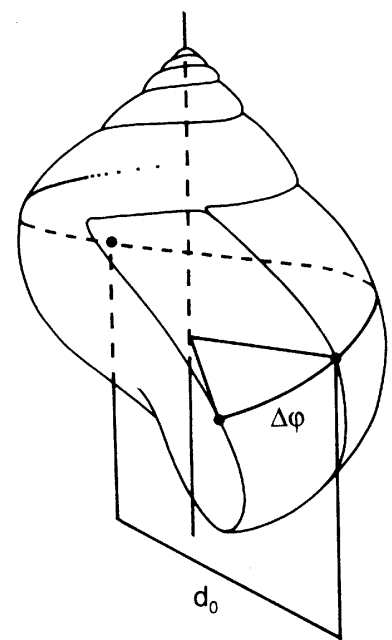

Figure 2. Diagram of shell measurements. $d_{0}$ denotes the shell width at the last growth interruption line, $\Delta \varphi$ denotes the angle increment in degrees from $\mathrm{d}_{0}$ to shell aperture.

\section{Data analysis}

Since the growth rate decreases with snail size (see Results), comparison of growth rates between infected and uninfected specimens was carried out by applying a paired $t$-test on pairs of snails with similar shell diameter at the last winter line $\left(\mathrm{d}_{0}\right)$. Such pairs were chosen randomly from the data base using a computer algorithm. Where growth rates differed between sexes (the Trend population) only individuals with similar sex were paired, and even numbers of males and females were applied in the analysis of growth rates of uninfected snails.

Statistical analysis were carried out using SPSS (Statistical Package for the Social Science) (Norusis, 1993). Prior to the paired $t$-tests, the assumption of normal distributed differences in growth between pairs of snails was assured. Following Kruskal-Wallis test, a posteriori multiple comparisons compensating for experimentwise error-rate were performed according to Siegel \& Castellan (1988).

\section{Evaluation of the method}

Because angle increment from an identified last growth interruption line on the shell as a measure of growth rate has been applied rarely on gastropods, it may be appropriate to comment on the advantages and disadvantages of this method. In comparison with the usually applied methods measuring changes in shell height (or width) during mark-recapture studies in the field or under controlled laboratory conditions, the present method has several advantages. (1) Measurements of angle increment is considerably more accurate than any measures of growth based on changes in shell height or width, especially when dealing with slowgrowing species or specimens. (2) The method avoids artifacts due to parasite-induced shell deformation unrelated to actual growth rate but nevertheless affecting shell height or width (Wesenberg-Lund, 1934; Rothschild, 1936; Sturrock \& Sturrock, 1970). (3) It avoids problems with spire erosion that might invalidate 

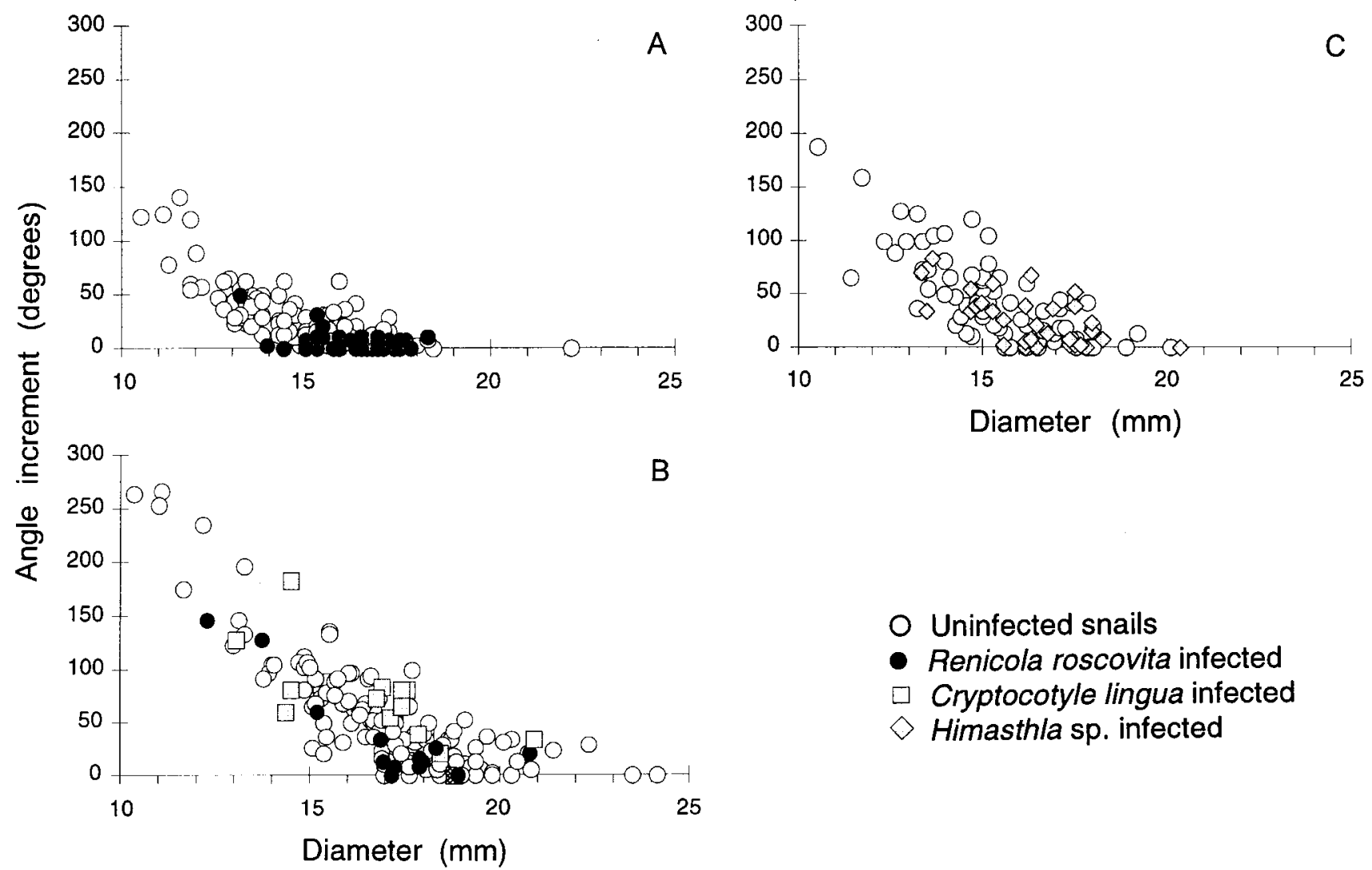

Figure 3. Angle increment $\left(\Delta \varphi\right.$, degrees) as a function of shell diameter $\left(\mathrm{d}_{0}\right)$ for infected and uninfected Littorina littorea snails collected at Rønbjerg (A), Grenå (B), and Trend $(\mathbf{C})$.

conclusions in mark-recapture studies where only shell height is measured (see for example Huxham et al., 1993). (4) Measurements of angle increment is easy and time saving, and there will be no problems with low rates of recapture usually experienced in mark-recapture studies. (5) In comparison with laboratory experiments the method benefits from its direct in situ approach thereby avoiding artefacts such as unrealistic availability of food (see for example Fernández \& Esch, 1991).

Beside the above advantages a disadvantage should also be recognized. The method assumes that all measured specimens have been infected (or uninfected) throughout the period from the formation of the last growth interruption line. If this is not true, it may contribute to a higher variance among infected individuals, which, in turn, may reduce the possibility of demonstrating a significant difference between infected and uninfected snails. The problem is, however, only relevant when no statistical difference can be demonstrated. Regarding the Littorina specimens collected in the present study, having ages of usually more than 4 y (see Discussion), the above assumption is reasonable. In populations of longer-lived snails, the trematode-infections seem to accumulate only very slowly (Curtis, 1996), which minimizes the probability that new infections arise during a single growth season or period.

Finally, it should be emphasized that the identification of the last growth interruption line, which is the critical point in using the method of angle increment, has shown to be a reasonably easy task both on Hydrobia (Gorbushin, 1997) and Littorina shells. That these lines actually represent a period of growth interruption or at least a suitable starting point for growth estimates, is demonstrated by the observation of the overall decrease in angle increment with increasing shell size in both Hydrobia and Littorina (see Gorbushin, 1997 and Results). Such a negative relationship between growth rate and size is perhaps the most notorious observation in studies of gastropod growth.

\section{RESULTS}

\section{Parasite location and host castration}

Four different trematode species were encountered during the study. Renicola roscovita, Cryptocotyle lingua, Microphallus pygmaeus and Himasthla sp. However, only infections by Renicola from Rønbjerg and Grenå, infections by Himasthla from Trend, and infections by Cryptocotyle from Grenå occurred in sufficiently high frequencies to allow further analysis.

The parasite species were located in the gonad-digestive gland complex usually leaving only a minor part unaffected. One exception was infections by Renicola, where the distribution of the orange ball-like masses of sporocysts were often rather restricted leaving large parts of the gonads and the digestive gland free of larval trematodes. However, Renicola together with the other encountered trematode species, caused an at least partial 
Table 1. Littorina littorea: summary statistics of paired t-tests on the difference between the growth rate of trematode-infected and uninfected snails from the three investigated populations.

\begin{tabular}{llcccccc}
\hline & & \multicolumn{5}{c}{ Growth $(\Delta \varphi)$} \\
\cline { 3 - 7 } Population & Trematode species & Infected & Uninfected & DIFF & $t$ & df & \multirow{2}{*}{$P$} \\
\hline Rønbjerg & Renicola roscovita & 4.8 & 17.1 & $-12.3 \pm 2.0$ & 6.09 & 45 & $<0.001$ \\
Trend & Himasthla sp. & 25.7 & 32.8 & $-7.1 \pm 5.0$ & 1.41 & 30 & 0.17 \\
Grenå & Renicola roscovita & 33.1 & 34.4 & $-1.3 \pm 5.6$ & 0.23 & 13 & 0.82 \\
& Cryptocotyle lingua & 64.7 & 56.1 & $8.7 \pm 7.9$ & 1.09 & 14 & 0.30 \\
\hline
\end{tabular}

$\Delta \varphi$, mean angle increment in degrees (see Materials and Methods); DIFF, mean difference $( \pm \mathrm{SE})$ in $\Delta \varphi) ; t$, test-value of the paired $t$-test; df, degrees of freedom; $P$, probability of no difference.

castration of the infected hosts in all populations studied, evidenced by significant smaller penis size among infected than among uninfected males (Student's $t$-test: $t>6.91$, $P<0.001)$. Among Grenå snails the mean penis length of uninfected was almost twice the length of infected.

\section{Trematode infection and growth}

The growth rates of the snails decreased with increasing shell size in all three populations (Figure 3). The influence of infection on the snails' growth rates differed according to trematode species and snail population. In the Rønbjerg population invasion by Renicola caused a significant reduction in growth rates in comparison with uninfected specimens, whereas in the Grenå population this trematode species had no significant effect on growth (Table 1). Also Cryptocotyle had no significant influence on the growth of snails from the Grenå population, which applied to Himasthla infections from the Trend population as well (Table 1).

The conclusion that Renicola infections affect growth rates differently in snails from Rønbjerg and Grenå rests on the evaluation of the paired $t$-tests carried out on quite different sample sizes $\left(\mathrm{N}_{\text {Rønbjerg }}=46, \mathrm{~N}_{\text {Grenå }}=14\right)$. This imbalance makes it more likely to show a significant effect in the Rønbjerg population than in the Grenå population due to more statistical power in the test of the former. Hence, a type II error is risked by accepting $\mathrm{H}_{0}$ (no difference) in the Grenå sample. However, a paired $t$-test carried out on the Rønbjerg sample embracing only 14 pairs as in the Grenå sample still arrives at a significant lower growth rate in infected than uninfected snails $\left(t_{13}=4.42, P=0.001\right)$. Moreover, based on the observed difference (and attached variation) in growth between uninfected and Renicola infected Grenå snails (see Table 1), a sample size of 952 pairs of snails had to be included in the test before the effect of the infection can be considered statistically significant. Together, these considerations demonstrates that the observed differential effect of Renicola infections between snails from Rønbjerg and Grenå is notable.

\section{Growth of uninfected snails}

The growth rates of uninfected snails differed significantly among the three populations (Kruskal-Wallis test: $\left.\chi^{2}=47.17, P<0.001\right)$. Snails from Grenå showed considerably higher growth rates $\left(\varphi=42^{\circ}, 0-135^{\circ}\right.$ [median, range],
$\mathrm{N}=101)$ than uninfected specimens from Trend $\left(\Delta \varphi=22^{\circ}\right.$, $\left.0-118^{\circ}, \mathrm{N}=50\right)$, and especially, Rønbjerg $\left(\Delta \varphi=13^{\circ}, 0-62^{\circ}\right.$, $\mathrm{N}=66)(P<0.05$ for all possible a posteriori comparisons). The analysis was restricted to snails between 14 and $19 \mathrm{~mm}\left(\mathrm{~d}_{0}\right)$ where uninfected specimens were reasonably abundant in all three populations studied. The observed difference in growth rates cannot be explained by any difference in skewness of size-distributions within the applied size-class.

\section{DISGUSSION}

The life history hypothesis

The present results provides field evidence for the absence of parasite-induced gigantism in Littorina littorea by showing that trematodes have no or even a negative effect on the snails' growth rates from three different populations/habitats. The result forms a contrast to the evidence of gigantism in Hydrobia spp. infected by species of trematodes from the same genera (Cryptocotyle and Himasthla) and investigated by the same method (Gorbushin, 1997). Together, these two studies support the life history hypothesis initially presented by Sousa (1983) (see Introduction) who did not find evidence for gigantism in a mark-recapture study of the iteroparous marine snail Cerithidea californica.

The evaluation of Sousa's hypothesis strives for at least a reasonably accurate determination of snail longevity. As opposed to the situation in bivalves, direct age-determination of gastropods has so far proven to be difficult or rarely attempted (see Williamson \& Kendall, 1981), and estimates of longevity are usually based on the analysis of size-frequency distributions. This may be adequate for the separation of annual and perannual life histories, but not appropriate for longer-lived species. In support of his hypothesis, Sousa (1983) mentioned Hydrobia ulvae as a semelparous short-lived species. Based on size-frequency analysis, H. ulvae has a longevity of 1-3 y depending on habitat (Chatfield, 1972; Fish \& Fish, 1974; Wolff \& de Wolff, 1977; Barnes, 1990; Mouritsen \& Jensen, 1994). However, using the presence of winter interruption lines on the Hydrobia shell, Gorbushin (1997) arrived at longevities of 3 and $4 \mathrm{y}$ in a Danish and a White Sea population, respectively. Hence, $H$. ulvae cannot be considered a semelparous species although its longevity is obviously much less than the 8-10y given for Cerithidea californica in Sousa's study. Regarding the longevity of Littorina littorea, only little has been reported. Moore (1937) arrived at $5+\mathrm{y}$ in a population at Plymouth, in general agreement 
with Hughes \& Answer (1982) mentioning 4.5+y in a population from north Wales. In captivity specimens of L. littorea has attained ages of up to $20 \mathrm{y}$ (Woodward, 1913). These numbers are generally in accordance with growth interruption lines found on the Littorina shell. In the White Sea, Littorina spp. are by routine aged according to such lines (see Sergievsky et al., 1991; Granovitch, 1992), and similar lines can be found on L. littorea also in the presently studied Danish populations. Our observations so far indicate that these growth interruption lines can be used in age-determination, and if applied, a major part of the snails collected in this study have ages of at least four (usually more) years. So, L. littorea as well as $H$. ulvae can be considered iteroparous species, the former having the largest longevity. Whether or not gigantism develops within a given snail species should therefore merely be viewed as a probability in the continuum between shorter-lived and longer-lived species. The former being more likely to develop gigantism when infected than the latter under the general assumption that longevity and annual energy investment in reproduction are negatively related.

Whereas the observations by Sousa (1983) on C. californica combined with ours on Hydrobia and Littorina support the life history hypothesis, the apparent absence of gigantism in situ in the semelparous freshwater snail Helisoma anceps (Fernández \& Esch, 1991) is difficult to reconcile with this hypothesis. As discussed below, several factors may interfere with the potential growth rates of infected snails, and some of those could be relevant also to the mark-recapture study of $H$. anceps. Moreover, Miksys \& Saleuddin (1987) found that castration actually accelerated growth rates in the closely related $H$. duryi, which suggests that the $H$. anceps-example may be a special case (see Gorbushin, 1997 for an alternative approach reconcilable with the $H$. anceps-example).

\section{The effect of habitat}

Snail life history is not the only factor that influences the growth rates of snails following trematode infection. Snails at different ages or infected by different trematode species may respond differently (Sousa, 1983; Fernández \& Esch, 1991; Gorbushin, 1997), and food availability can also be expected to affect the growth rates of infected individuals (Fernández \& Esch, 1991; Mouritsen \& Jensen, 1994). The latter is now supported by Gorbushin (1997) showing that the growth of infected Hydrobia can be mediated by competitive interactions. Mouritsen \& Jensen (1994) also argued that to the extent that food availability was important, the effect of parasites on growth rates might not be exclusively species-specific but also vary between subpopulations of the same species. This prediction has received support regarding Hydrobia (Gorbushin, 1997), and the importance of a habitat/population dependent effect is further evidenced by the present results showing that L. littorea infected by Renicola roscovita grew at a lower rate than uninfected snails at Rønbjerg, whereas no difference was found between Renicola infected and uninfected snails at Grenå.

Food seems to be a limited resource to L. littorea, that often subsist under intraspecific explorative competition (Hylleberg \& Christensen, 1977a, who also studied the
Rønbjerg population). Hence, the discrepancy between Rønbjerg and Grenå regarding the growth of infected snails could be due to differences in the abundance of food or in the time available for feeding. This is tentatively supported by the much higher growth rate at Grenå than at Rønbjerg of uninfected snails. Grenå and Rønbjerg are east and west facing habitats, respectively, and since the prevailing wind direction in Denmark is westerly, Rønbjerg is considerably more exposed to windinduced wave-action than the more sheltered Grenåhabitat. Such environmental difference between habitats is likely to affect the time available for feeding in optimal microhabitats. On exposed shores Littorina snails regularly have to abandon optimal feeding sites in order to avoid wave-induced dislodgement (Boulding \& Van Alstyne, 1993). On a seasonal basis this should produce growth rates below the potential for the habitat. It has to be acknowledged, however, that between-habitat differences in the growth of littorinoids are influenced by a number of factors other than just food availability (Hylleberg \& Christensen, 1977b; Johannesson, 1986; Boulding \& Van Alstyne, 1993; Reid 1996, and references therein). Additional studies are therefore necessary before it can be clarified whether food availability is a main reason for the differential effect of trematode infection on growth rates between different populations of L. littorea.

\section{Future studies}

Since it is documented that parasite-induced gigantism is a naturally occurring phenomenon and that growth rates following parasitic castration depend among other things on host species and habitat, further field studies may contribute only little to the evaluation of the validity of the life history hypothesis. The relative amount of energy allocated to growth and reproduction along the axis of snail longevity should within the frame-work of life history theory at least initially be genetically embodied (Stearns, 1992). Hence, the critical test of Sousa's hypothesis should show that, following parasitic castration, shorter-lived snails have an inherent ability to grow at a faster rate than longer-lived species under also optimal conditions. This is best done in the laboratory under controlled conditions (including access to ad libitum food) thereby excluding confounding effects of various environmental factors.

We wish to thank Tomas Jensen, Peter Middelfart, Lone T. Mouritsen, and referees for constructive comments. The study was supported financially by a grant to K.N.M. and K.T.J. from the Carlsberg Foundation, and partly by the Russian Foundation of Basic Research (RFBR, grant no. 96-04-48-965).

\section{REFERENCES}

Barnes, R.S.K., 1990. Reproductive strategies in contrasting populations of the coastal gastropod Hydrobia ulvae. II. Longevity and life-time egg production. Fournal of Experimental Marine Biology and Ecology, 138, 183-200.

Boulding, E.G. \& Van Alstyne, K.L., 1993. Mechanisms of differential survival and growth of two species of Littorina on wave-exposed and on protected shores. Fournal of Experimental Marine Biology and Ecology, 169, 139-166. 
Chatfield, J.E., 1972. Studies on variation and life history in the prosobranch Hydrobia ulvae (Pennant). Fournal of Conchology, 27, 463-473.

Crews, A.E. \& Yoshino, T.P., 1989. Schistosoma mansoni: effect of infection on reproduction and gonadal growth in Biomphalaria glabrata. Experimental Parasitology, 68, 326-334.

Curtis, L.A., 1996. The probability of a marine gastropod being infected by a trematode. Fournal of Parasitology, 82, 830-833.

Fernández, J. \& Esch, G.W., 1991. Effect of parasitism on the growth rate of the pulmonate snail Helisoma anceps. Fournal of Parasitology, 77, 937-944.

Fish, J.D. \& Fish, S., 1974. The breeding cycle and growth of Hydrobia ulvae in the Dovey Estuary. Fournal of the Marine Biological Association of the United Kingdom, 54, 685-697.

Gorbushin, A.M., 1997. Field evidence of trematode-induced gigantism in Hydrobia spp. (Gastropoda: Prosobranchia). Fournal of the Marine Biological Association of the United Kingdom, 77, 785-800.

Granovitch, A.I., 1992. The effect of trematode infections on the population structure of Littorina saxatilis (Olivi) in the White Sea. In Proceedings of the Third International Symposium on Littorinid Biology (ed. P.J.M. Graham and D.G. Reid), pp. 255-263. London: The Malacological Society.

Hughes, R.N. \& Answer, P., 1982. Growth, spawning and trematode infections of Littorina littorea (L.) from an exposed shore in north Wales. Fournal of Molluscan Studies, 48, 321-330.

Huxham, M., Raffaelli, D. \& Pike, A.W., 1993. The influence of Cryptocotyle lingua (Digenea: Platyhelminthes) infections on the survival and fecundity of Littorina littorea (Gastropoda: Prosobranchia); an ecological approach. Fournal of Experimental Marine Biology and Ecology, 168, 223-238.

Huxham, M., Raffaelli, D. \& Pike, A.W., 1995. The effect of larval trematodes on the growth and burrowing behaviour of Hydrobia ulvae (Gastropoda: Prosobranchia) in the Ythan Estuary, north-east Scotland. Fournal of Experimental Marine Biology and Ecology, 185, 1-17.

Hylleberg, J. \& Christensen, J.T., 1977a. Factors affecting the intra-specific competition and size distribution of the periwinkle Littorina littorea (L.). Nature futlandica, 20, 193-202.

Hylleberg, J. \& Christensen, J.T., 1977b. Phenotypic variation and fitness of periwinkles (Gastropoda: Littorinidae) in relation to exposure. Fournal of Molluscan Studies, 43, 192-199.

Johannesson, B., 1986. Shell morphology of Littorina planaxis Olivi: the relative importance of physical factors and predation. Fournal of Experimental Marine Biology and Ecology, 102, 183-195.

McClelland, G. \& Bourns, T.K.R., 1969. Effects of Trichobilharzia ocellata on growth, reproduction, and survival of Lymnaea stagnalis. Experimental Parasitology, 24, 137-146.

Meuleman, E.A., 1972. Host-parasite inter-relationships between the freshwater pulmonate Biomphalaria pfeifferi and the trematode Schistosoma mansoni. Netherlands Fournal of Zoology, 22, 355-427.

Miksys, S.L. \& Saleuddin, A.S.M., 1987. Effects of castration on growth and reproduction of Helisoma duryi (Mollusca: Pulmonata). International Fournal of Invertebrate Reproduction and Development, 12, 145-160.

Moore, H., 1937. The biology of Littorina littorea. Part I. Growth of the shell and tissues, spawning, length of life and mortality. Fournal of the Marine Biological Association of the United Kingdom, 21, 721-742.
Mouritsen, K.N. \& Jensen, K.T., 1994. The enigma of gigantism: effect of larval trematodes on growth, fecundity, egestion and locomotion in Hydrobia ulvae (Pennant) (Gastropoda: Prosobranchia). Journal of Experimental Marine Biology and Ecology, 181, 53-66.

Norusis, M.J., 1993. SPSS for Windowes: base system user's guide, Release 6.0. Chicago: SPSS Inc.

Reid, D.G., 1996. Systematics and evolution of Littorina. Andover: The Ray Society.

Rothschild, M., 1936. Gigantism and variation in Peringia ulvae Pennant 1777, caused by infection with larval trematodes. Fournal of the Marine Biological Association of the United Kingdom, 20, 537-546.

Rothschild, A. \& Rothschild, M., 1939. Some observations on the growth of Peringia ulvae (Pennant) 1777 in the laboratory. Novitates Zoologicae, 41, 240-247.

Sergievsky, S.O., Granovitch, A.I. \& Mikhailova, N.A., 1991. The age structure of White Sea populations of Littorina obtusata and L. saxatilis. Trudy Zoologicheskogo Instituta, 223, 79-126. [In Russian.]

Siegel, S. \& Castellan, N.J. Jr, 1988. Nonparametric statistics for the behavioral sciences. New York: McGraw-Hill.

Sluiters, J.F., Brussaard-Wüst, C.M. \& Meuleman, E.A., 1980. The relationship between miracidial dose, production of cercariae, and reproductive activity of the host in the combination Trichobilharzia ocellata and Lymnaea stagnalis. Zeitschrifte für Parasitenkunde, 63, 13-26.

Sousa, W.P., 1983. Host life history and the effect of parasitic castration on growth: a field study of Cerithidea californica Haldemann (Gastropoda: Prosobranchia) and its trematode parasites. Fournal of Experimental Marine Biology and Ecology, 73, 273-296.

Stearns, S.C., 1992. The evolution of life histories. Oxford: Oxford University Press.

Sturrock, R.F. \& Sturrock, B.M., 1970. Shell abnormalities in Biomphalaria glabrata infected with Schistosoma mansoni and their significance in field transmission studies fournal of Helminthology, 45, 201-210.

Werding, B., 1969. Morphologie, Entwicklung und Ökologie digener Trematoden-Larven der Strandschnecke Littorina littorea. Marine Biology, 3, 306-333.

Wesenberg-Lund, C.J., 1934. Contribution to the development of the trematode digenea. Part II. The biology of the freshwater cercariae in Danish freshwaters. Det Kongelige Danske Videnskabelige Selskabs Skrifter, 5, 1-223.

Williamson, P. \& Kendall, M.A., 1981. Population age structure and growth of the trochid Monodonta lineata determined from shell rings. Fournal of the Marine Biological Association of the United Kingdom, 61, 1011-1026.

Wilson, R.A. \& Denison, J., 1980. The parasitic castration and gigantism of Lymnaea truncatula infected with the larval stages of Fasciola hepatica. Zeitschrifte für Parasitenkunde, 61, 109-119.

Wolff, W.J. \& Wolff, L. de, 1977. Biomass and production of zoobenthos in the Gevelingen Estuary, The Netherlands. Estuarine and Coastal Marine Science, 5, 1-24.

Woodward, B.B., 1913. The life of the Mollusca. London: Methuen. 